4

5

6

7

8

9

10

11

12

13

14

15

16

17

18

19

20

21

22

23

24

25

26

\title{
THE EFFECT OF CELLULOSE AND STARCH ON THE VISCOELASTIC AND THERMAL PROPERTIES OF ACID- SWOLLEN COLLAGEN PASTE
}

M Sobanwa $^{1}$, T J Foster ${ }^{1}$, N J Watson ${ }^{2 *}$

${ }^{1}$ Division of Food Sciences, The University of Nottingham, Sutton Bonington Campus,

Loughborough LE12 5RD, United Kingdom.

${ }^{2}$ Food, Water, Waste Research Group, Faculty of Engineering, The University of Nottingham,

University Park Campus NG7 2RD, United Kingdom.

33 ${ }^{*}$ Corresponding author: Nicholas.Watson@nottingham.ac.uk 
Collagen pastes are processed materials obtained through the swelling of minced bovine hides using acids into a fibrous swollen structure. Depending on the application, there is a need to improve the performance of these pastes in terms of rheological properties and mechanical strength of the final product. In this work, the addition of cellulose fibres and starch granules as fillers in acid swollen collagen paste was investigated. The influence of cellulose fibre length and starch granules with different amylose and amylopectin content on the viscoelastic and thermal properties of acid swollen paste were studied as a function of mixing ratio and collagen paste concentration. Addition of cellulose and starch granules resulted in an increase in the elastic modulus of the collagen paste with the starch granules having the highest impact. Addition of cellulose and starch also affected the tan $\delta$ peak of collagen paste at different collagen concentrations as a function of temperature. The micro differential scanning calorimetry (microDSC) results indicated that the denaturation temperature value of collagen was not influenced by the presence of cellulose and starch. However, upon reheating the denaturation temperature of collagen pastes wit starch granules shifted to lower temperatures.

Keywords: Corn starch, Denaturation, Rheology, Micro differential scanning calorimetry 49 (DSC). 


\section{INTRODUCTION}

53 Collagen is the major structural protein of connective tissues such as tendons, bones and skins. It consists approximately $30 \%$ of the total protein in human and animal bodies (Hashim et al., 2015). At least 27 forms of collagen have been identified in mammalian tissue of which collagen type 1 has been identified as the major structural component of the connective tissue (Pati et al., 2010;Zhang et al., 2010;Wang et al., 2017). Collagen's primary structure consists of repeating units of glycine (Gly)-proline (X)-hydroxyproline(Y). The collagen molecule is made of three polypeptide chains which are coiled in a left-handed helix, these chains are further twisted into a right-handed superhelix that are stabilised by hydrogen bonds (KomsaPenkova et al., 1996;Schroepfer and Meyer, 2017). Due to its unique properties, such as weak antigenicity, biodegradability, biocompatibility, bioactivity and tensile strength, collagen has been extracted into different forms such as gels, pastes, films, sponges and fibres. It is widely used in the food, pharmaceutical, chemical and cosmetics industries and for scaffolds in tissue engineering (Friess, 1998;Ding et al., 2014). However, there are a number of challenges such as low thermal stability and poor water vapour barrier properties, which limits wider applications (Bigi et al., 2004;Mu et al., 2007). A possible means to circumvent the suboptimal properties of collagen and increase its application, is to incorporate other natural polymers such as polysaccharide fibres or fillers (Wang et al., 2018). These will act as a reinforcement by enhancing the strength, barrier properties and thermal stability of the resulting composite structures (Wolf et al., 2009) . In the food industry, collagen type 1 has been extracted into a paste that is used for sausage casings. Collagen casings have been applied successfully as an alternative to the relatively high cost of casings made from animal intestines (Barbut, 2010). There is an interest in modifying the mechanical properties of collagen casings through the addition of natural biopolymers such as cellulose fibres and starch granules. These natural biopolymers are of a particular interest as particulate fillers due to their natural abundance, biodegradability, and low cost (Ding et al., 2014;Basiak et al., 2017). They have also been shown to provide great reinforcement to polymer matrices due to their high mechanical 
strength (Dufresne and Vignon, 1998;Bledzki and Gassan, 1999). Cellulose is the most abundant natural polymer on earth and is a major component of cell walls of higher plants and some bacteria, such as Acetobacter Xylinum strains. Cellulose possess a complex and highly ordered chemical structure akin to that of collagen giving high mechanical strength, albeit of polysaccharide rather than protein origin. It is a linear homopolymer composed of $\beta$-Dglucopyranose units linked with $\beta-1,4$ glycosidic linkages. It is used in the food industry as a texturiser, non-caloric bulking agent, thickener, stabiliser and raising agent (Yoon and Lee, 1990;Ang and Miller, 1991;Harris and Smith, 2006).

Starch is a well-known storage carbohydrate and is found in the form of insoluble granules within plant cells (Sullo and Foster, 2010). Semi-crystalline starch granules are made up of two polysaccharides. The first is amylose which contains the amorphous region of the granule and has long linear (1-4) linked $\alpha$-D-glucopyranose residues. The second is amylopectin, which is composed mainly in the crystalline region of the granule and is a highly branched molecule consisting of shorter chains of (1-4) $\alpha$-D-glucopyranose residues with (1-6) - $\alpha$-Dglycosidic branched linkages (Buléon et al., 1998;Jane et al., 1999). Starch is obtained from various sources such as cereal, tuber and root crops and used in wide range of applications, such as food, pharmaceutical, paper and plastic. Starch has unique physicochemical and functional properties hence it is used as a thickener, colloidal stabiliser, gelling agent, adhesive and water retention agent in various industries (Singh et al., 2003;Copeland et al., 2009). In recent years, there has been an increased interest in the blending of collagen with other natural biopolymers in order to develop products with new and modified functional properties as well as providing cost and processing advantages. Several studies demonstrated that the addition of polysaccharides into collagen solutions can modify the thermal and rheological properties of collagen solutions. (Ding et al., 2014) reports enhancement upon the Hydroxypropyl Methylcellulose (HPMC) improved the on the rheological and thermal stability of collagen solutions and was attributed to a hydrogen bond interactions as well as a compatibility between the collagen and HPMC molecules. Nicoleti and Telis (2009) reported that concentrations of about $0.1 \%$ xanthan gum increased the gel strength of collagen solution, 
when heated. Increasing the concentration of xanthan to about $0.3 \%$ resulted in a weaker gel while the addition of Maltodextrin led to a more fluid-like structure and this was suggested to be due to the thermodynamic incompatibilities between the biopolymers. Similarly, Oechsle et al. (2015) studied the influence of incorporating co-gelling biopolymers of different molecular weights; low molecular weight ( whey protein isolate and blood plasma protein), or high molecular weight (soy protein isolate and gluten) into a collagen matrix and they reported that they displayed effects when added to the collagen gels, affecting the collagen network and embedding within it.

Therefore, the aim of this study was to understand how the addition of cellulose with different fibre lengths and starch granule fillers affects the viscoelastic and thermal properties of acid swollen collagen pastes. The viscoelastic properties were investigated using small oscillation rheological measurements and the thermal changes were studied using a microDSC. Both rheological and thermal measurements were studied as a function of collagen paste concentration. The effect of biopolymer morphology and aspect ratios was also considered. The hypothesis underpinning this research is that the viscoelastic and thermal properties can be modified by the addition of non-charged polysaccharides. Also, it was hypothesised that similar effect will be observed when the phase volumes of the polysaccharide are matched.

\section{Materials and Methods}

\subsection{Materials}

Two types of cellulose with different aspect ratios were used in this study i.e. Solka-Floc 300 (SF3) and Solka-Floc 900 (SF9) with fibre lengths of 22 and $100 \mu \mathrm{m}$ respectively. Cellulose powders were supplied by the International Fibre Corporation (New York, USA). Two types of starches with different amylose and amylopectin contents were used, waxy maize starch (WS: 1-2\% amylose) and high amylose starch (HAS: 70\% amylose) were both supplied by Ingredion (Manchester, UK). A pH 2.0 acid $(\mathrm{HCl})$ swollen paste was made from fibrous collagen donated by Devro plc (Scotland, UK). 


\subsection{Determination of Phase Volume (Ф)}

134 The phase volume of cellulose and starch dispersions were measured by centrifugation

135 (Thermo Electron Corporation, Ohio, USA) using a centrifugation force of $2000 \mathrm{~g}$ for 20 mins

136 at $20{ }^{\circ} \mathrm{C}$. Cellulose and starch dispersions at a total solid concentration ranging from $1 \%$ to

$1377 \%$ were transferred into $50 \mathrm{ml}$ conical bottom centrifuge tubes. After centrifugation, the total 138 height $H_{T}$ of the sample and the height of the sediment $H_{S}$ were measured and the phase 139 volume of the cellulose and starch dispersions were calculated by the total height divided by 140 the height of the sediment. The concentrations of cellulose and starch dispersions needed for 141 a 15\% phase volume were extrapolated from a graph of phase volume against concentration 142 (not shown).

\subsection{Preparation of Collagen-Cellulose and Collagen-Starch blends.}

144 The concentrations of cellulose and starch (refer to Error! Reference source not found.) corresponding to a phase volume of $15 \%$ were prepared by dispersing the powders in deionised water. The dispersions were mixed with collagen paste at different collagen/cellulose (solka floc 300 and solka floc 900) and collagen/starch (waxy starch and high amylose starch) mixing ratios i.e., 80:20, $70: 30$ and 50:50. The final concentrations of the collagen pastes at the various mixing ratios were $4 \%(\mathrm{w} / \mathrm{w}), 3.5 \%(\mathrm{w} / \mathrm{w})$ and $2.5 \%(\mathrm{w} / \mathrm{w})$. The collagen paste with cellulose dispersions and starch dispersions were mixed by gently stirring at room temperature for 15 mins using an overhead stirrer (yellow line IKA OST 20 high torque Overhead Stirrer). The $\mathrm{pH}$ of the final blends was between 2 and 2.5. Samples were degassed using an Audionvac VMS 53 multivac vacuum packager (Audion Elektron, Netherlands) in order to remove the air bubbles incorporated during mixing, before further analyses were performed. The blends formulation and sample code is shown in Table 1. 
157 Table 1. Formulation of collagen-cellulose and collagen-starch blends at various mixing ratios 158 and different concentrations of collagen. SF3 $=$ Solka floc 300, SF9 $=$ Solka floc 900, WS $=$ 159 Waxy starch, HAS = High amylose starch, $\Phi=$ phase volume

160

\begin{tabular}{lll}
\hline Collagen Paste: & Conc. of Collagen in the & Conc. (\%wt) of cellulose \\
Suspension & mixture (\%wt) & $\begin{array}{l}\text { and starch for } \Phi=15 \% \text { in } \\
\text { the mixture (\%wt) }\end{array}$ \\
&
\end{tabular}

$\begin{array}{lll}\text { 80:20 CollSF3 } & 4 & 2.7 \\ \text { 80:20 CollSF9 } & & 1.8 \\ \text { 80:20 CollWS } & & 7 \\ \text { 80:20 CollHAS } & & 6.6\end{array}$

70:30 CollSF3

3.5

2.7

70:30 CollSF9

1.8

70:30 CollWS

7

70:30 CollHAS

6.6

50:50 CollSF3

2.5

2.7

50:50 CollSF9

1.8

50:50 CollWS

7

50:50 CollHAS

6.6

161

162

163

164

165

166

\subsection{Measurement of paste viscoelasticity}

167 Small amplitude oscillatory rheology of the collagen pastes with and without cellulose/starch was performed using a controlled stress rheometer (Physica MCR 301, Anton Paar, Austria), 
using a parallel plate (diameter $50 \mathrm{~mm}$, gap $1.5 \mathrm{~mm}$ ) geometry. To prevent the pastes from

170 drying during the experiment, the edges of the measuring geometry was covered using a low

171 viscosity mineral oil, which is known to have no effect on the rheological measurements. The samples were equilibrated for 5 mins before measurements were conducted, this was performed in order to prevent temperature variations within the samples. The dynamic viscoelastic measurements were performed by subjecting the samples to various profiles: (i) amplitude sweeps were conducted at a constant angular frequency (10 rad/s) to determine the maximum deformation attained by the sample in the linear viscoelastic range (ii) frequency sweeps were performed from $0.1-100 \mathrm{rad} / \mathrm{s}$ at $20^{\circ} \mathrm{C}$ and a constant strain of $0.1 \%$ (selected from LVE region) (iii) dynamic temperature sweeps were conducted at a constant strain of $0.1 \%$ and frequency of $10 \mathrm{rad} / \mathrm{s}$. Collagen pastes with/without cellulose and starch were heated from 5 to $80^{\circ} \mathrm{C}$ at a rate of $5^{\circ} \mathrm{C} / \mathrm{min}$. The storage modulus (G'), loss modulus (G'), and loss factor ( $\left.\tan \delta=\mathrm{G}^{\prime} / \mathrm{G}^{\prime} /\right)$ were recorded as a function of frequency or temperature. The data reported represent the mean values from three replicates.

\subsection{Differential Scanning Calorimeter (microDSC)}

184 The denaturation temperature $\left(T_{d}\right)$ of the pastes was determined using a micro DSC

185 (MicroDSC III, SETARAM Instrumentation, Calurie, France). Approximately $0.8 \mathrm{~g}$ of the 186 samples were weighed into Hastelloy cells and sealed with O rings and Hastelloy screw tops. 187 Samples were loaded in the DSC instrument at $20^{\circ} \mathrm{C}$ and then cooled to $3^{\circ} \mathrm{C}$ at $1^{\circ} \mathrm{C} / \mathrm{min}$. Collagen pastes with/without cellulose and starch were heated up to $95^{\circ} \mathrm{C}$. Samples were then held at $95^{\circ} \mathrm{C}$ for 15 mins and cooled down to $3^{\circ} \mathrm{C}$ and reheated to $95{ }^{\circ} \mathrm{C}$ at $1^{\circ} \mathrm{C} / \mathrm{min}$. A

190 Hastelloy cell filled with RO water was used as a reference. The onset $\left(T_{O}\right)$, offset, peak 191 temperatures $\left(T_{P}\right)$ and enthalpy of transition $(\Delta H)$ were processed using Calisto Processing 192 software v1.43 (AKTS, Switzerland). The peak temperature of the thermogram was taken as 193 the melting or denaturation temperature of collagen. Runs were performed in duplicate and 194 the average and standard deviation reported. 
$195 \quad 2.6$ Statistical analysis

196 A one-way ANOVA was used to determine the difference between samples using Statistical 197 Package for Social Science Software (SPSS Inc.). When there were any differences between 198 samples, Tukey's test was used to determine the significance of the average $(P<0.05)$. 199 


\section{Results and Discussion}

\section{$201 \quad 3.1$ Dynamic Frequency Sweep}

202 Figure 1 and Figure 2 shows the frequency dependency of the storage modulus (G'), the loss 203 modulus (G") and the loss tangent (tan $\delta$ ) for COLLSF9, COLLSF3, COLLWS and COLLHAS

204

205

206

207

208

209

210

211

212

213

214

215

216

217

218

219

220

221

222

223

224

225 pastes at the different mixing ratios and collagen concentrations. The mechanical spectra of collagen pastes with the addition of starch granules and cellulose fibres at all mixing ratios showed that all the pastes had a solid like behaviour as the storage modulus was higher than the loss modulus throughout the frequency range investigated. This is the typical behaviour of biopolymer gel where G' (storage modulus) is usually greater than the G" (loss modulus) at the range of angular frequencies investigated (Ross-Murphy, 1995). Similar behaviour has also been reported by (Oechsle et al., 2015) who studied the influence of gluten, soy isolate and blood plasma proteins on the viscoelastic properties of collagen gels. The magnitude of the dynamic mechanical spectra of the collagen paste was modified after the addition of cellulose and starch, although the enhancement in G' was dependent on collagen concentration. COLLWS and COLLHAS pastes had higher values of storage modulus than that of collagen/cellulose pastes which suggests that the addition of starch promoted the formation of a stronger network structure (Figure $1 \mathrm{~A}-\mathrm{C}$ ). However, at mixing ratio of 80:20 the effect of starch was more pronounced than cellulose and this was attributed to the poor dispersibility of the cellulose fibres in the collagen matrix. Ahmed and Jones (1990) reported that the viscoelastic properties of composite materials are dependent on factors such as size, shape, concentration and distribution of the reinforcing polymers. Thus, the higher storage modulus observed for COLLWS and COLLHAS pastes might be due to the higher concentration of starch granules needed to match the phase volume of cellulose, as well as differences in particle shape, sizes, and packing. Also, according to (Tatsumi et al., 2002), it was reported that fibre suspensions would give higher elasticity than spherical suspensions when matched at equal volume concentration. In contrast, results of this study show that when 
starch granules and cellulose fibres were compared at the same phase volume, starch

227 granules were more effective at reinforcing the elastic modulus of acid swollen collagen pastes. In addition, at all the mixing ratios studied, cellulose fibres with longer (COLLSF9) and shorter (COLLSF3) fibre lengths both had similar effects on the G' and G" of the pastes. This could be attributed to the fact that the volume fraction of the shorter fibre length (SF3) and longer fibre length (SF9) were matched in the final mixtures at all the mixing ratios studied. Hemar et al. (2011) indicated that the rheological behaviour of dispersions is related to the volume fraction that the particles occupy. Moreover, if the volume fraction of the cellulose fibers with different fibre lengths were not matched, differences in their packing densities and aspect ratios might have an effect on the viscoelastic properties of collagen. Philipse (1996) reported that the packing densities of high aspect ratio rod-like colloids are lower compared to rods with small aspect ratios. . The tan $\delta$ values of the blends at the various formulations were lower than one which indicates that the elastic component dominated over the viscous component (Figure $2 \mathrm{~A}-\mathrm{C}$ ). The $\tan \delta$ value was dependent on the collagen concentrations,

240 higher tan $\delta$ values were observed for COLLSF3, COLLSF9, COLLWS and COLLHAS pastes at a ratio of $50: 50$ (2.5\% collagen concentration). This indicates that the pastes were weaker in structure as compared to pastes at ratios 80:20 (4\% collagen concentration) and 70:30 (3.5\% collagen concentration). The most striking observation to emerge from the $\tan \delta$ data is the difference in the tan $\delta$ shape at the various formulations. The $\tan \delta$ values of collagen with cellulose and starch mixed at a ratio of $80: 20$ and 70:30 decreased when the oscillation frequency increased from 0.1 to 1 angular frequency with a further increase in tan $\delta$ values at

247 higher frequencies. A similar frequency dependency of tan $\delta$ was found for chicken-wheat 248 flour doughs (Mohammed et al., 2011). However, at a ratio of 50:50, tan $\delta$ values decreased when the frequency increased from 0.1 to 10 angular frequency and was almost constant at higher frequencies. This indicates that the pastes were solid-like when a slow change in stress is imposed but when subjected to fast motions the pastes behaves more like a liquid . 
(A)

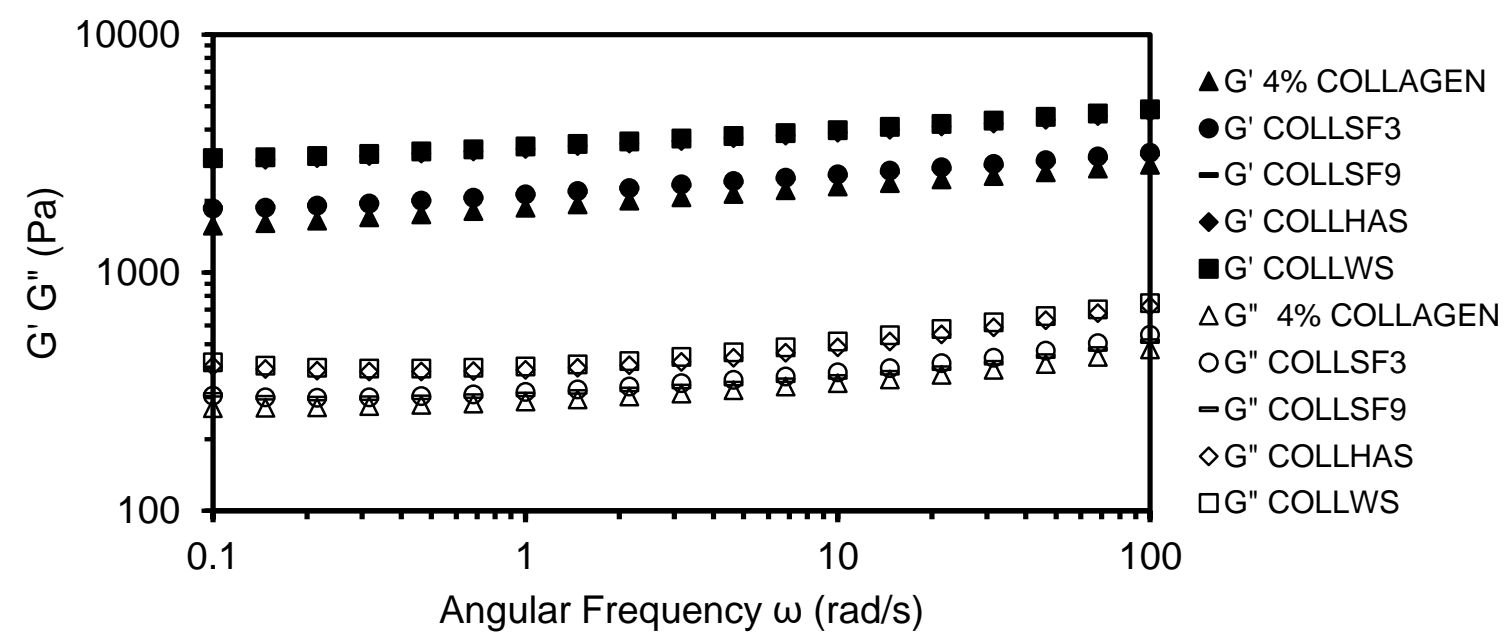

(B)

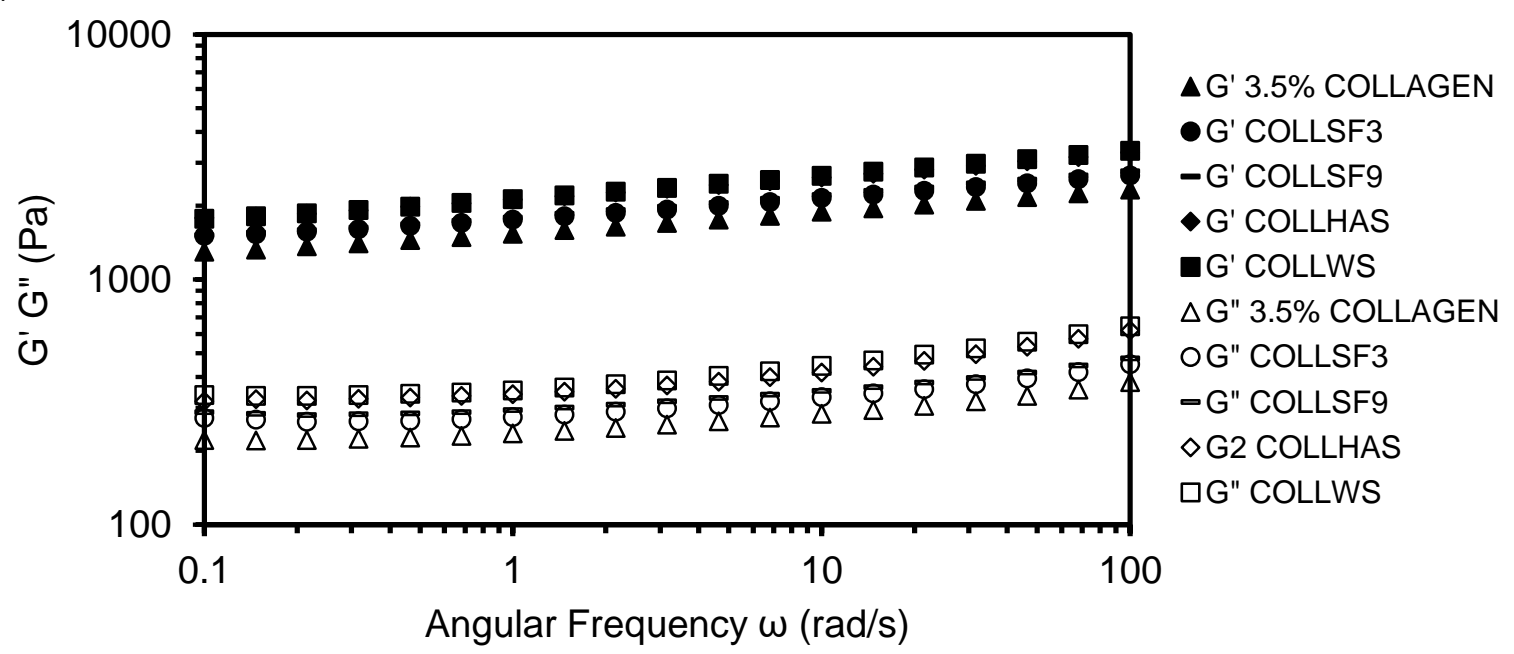

(C)

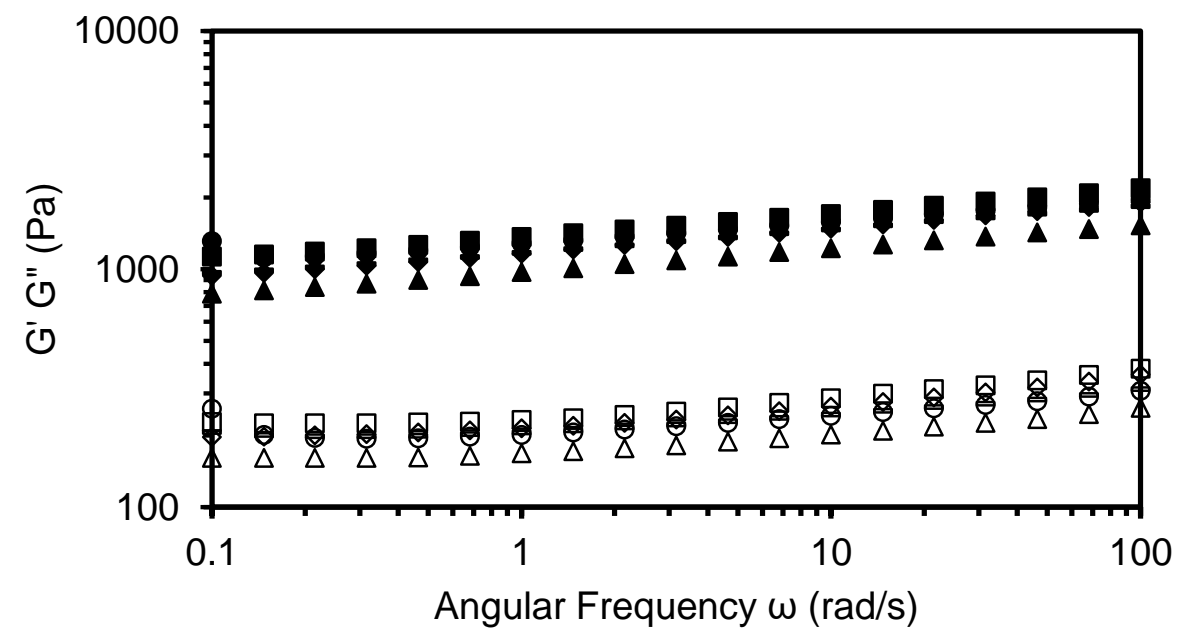

$\triangle G^{\prime} 2.5 \%$ COLLAGEN - G' COLLSF3

- G' COLLSF9 - G' COLLHAS - G' COLLWS $\triangle$ G" 2.5\% COLLAGEN OG" COLLSF3 - G" COLLSF9 $\diamond$ G" COLLHAS $\square$ G" COLLWS 
264

267

(C)

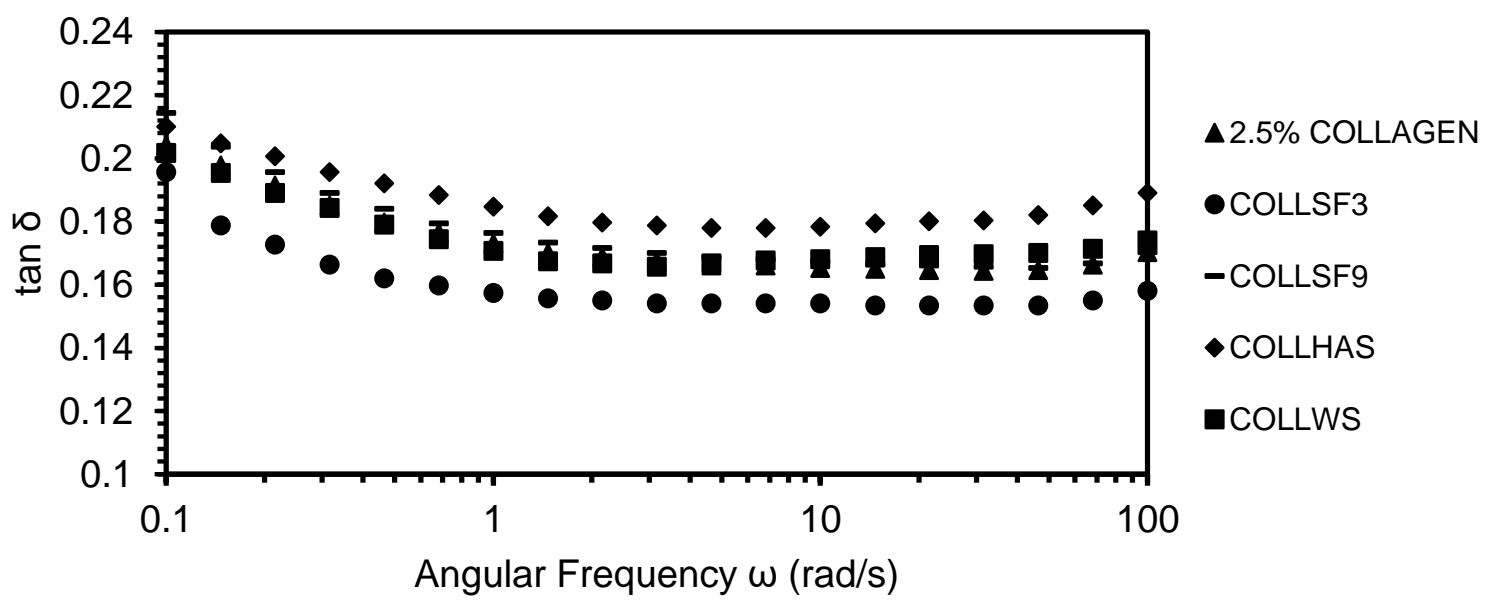

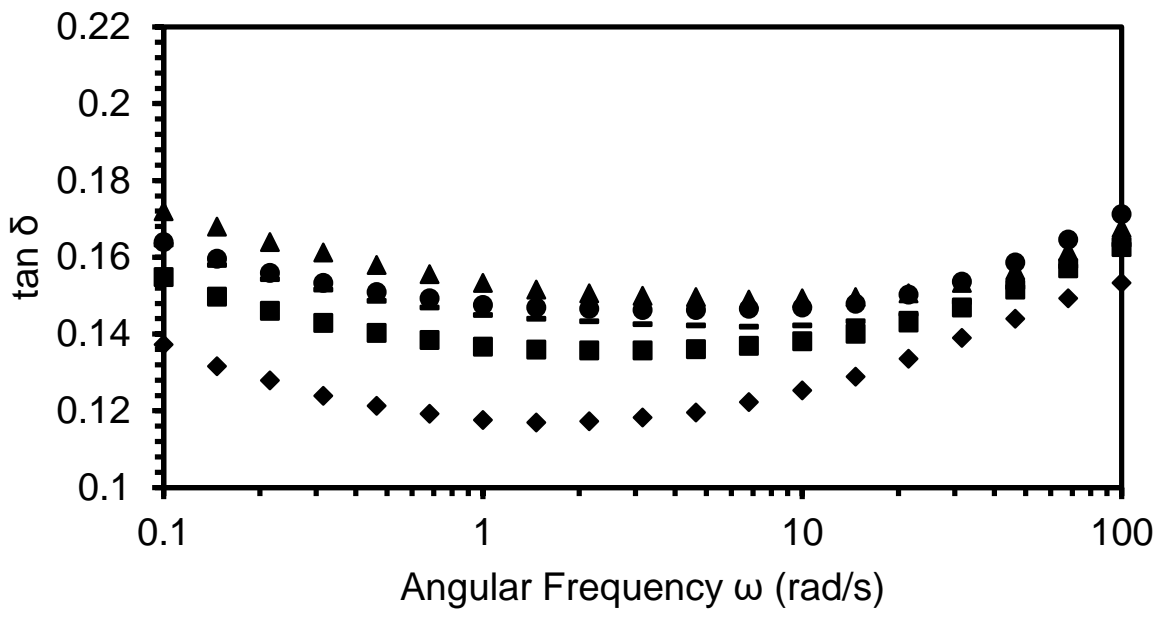

$\triangle 4 \%$ COLLAGEN

- COLLSF3

-COLLSF9

- COLLHAS

- COLLWS

(B)

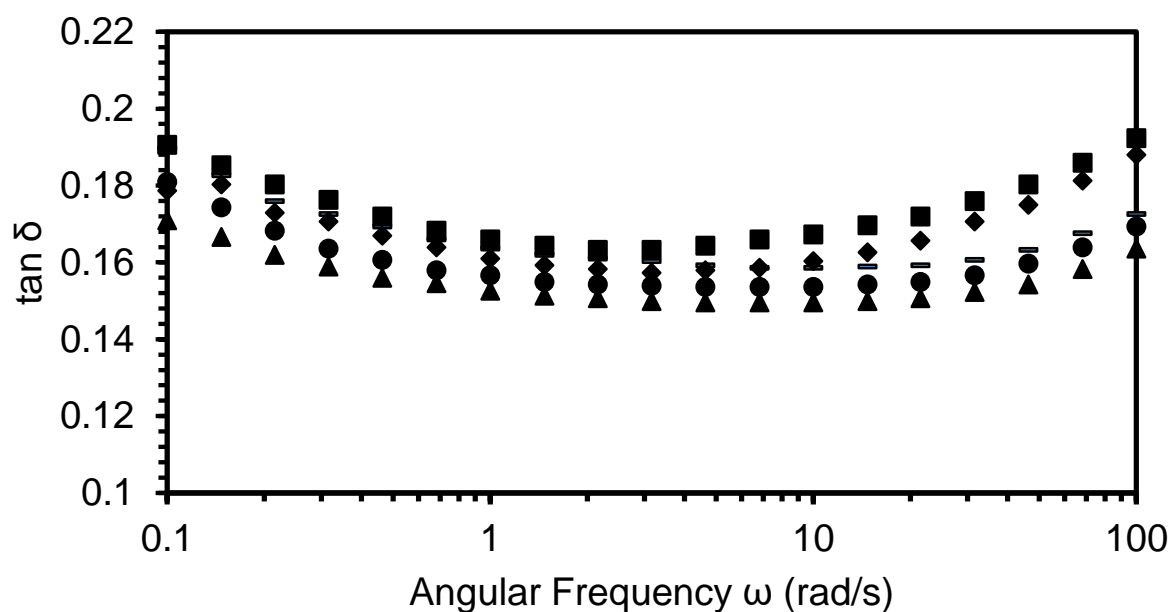

$\Delta 3.5 \%$ COLLAGEN

- COLLSF3

- COLLSF9

- COLLHAS

- COLLWS 


\section{$275 \quad 3.2$ Dynamic Temperature Sweep}

276 Error! Reference source not found.Figure 3 and Figure 4 shows the changes in storage

277 modulus (G'), loss modulus (G') and loss factor (tan $\delta$ ) of COLLSF3, COLLSF9, COLLWS 278 and COLLHAS pastes at various collagen concentrations as a function of temperature. All the 279 samples at the various mixing ratios showed no changes in $G^{\prime}$ with stable $\tan \delta$ values at 280 temperatures from $10{ }^{\circ} \mathrm{C}$ to $33^{\circ} \mathrm{C}$, however, the G'rapidly decreased at approximately $34{ }^{\circ} \mathrm{C}$

281 (Figure 3) with a corresponding increase in tan $\delta$ (Figure 4). Similar behaviour was observed when a collagen solution was studied as a function of concentration and temperature (Lai et al., 2008). This behaviour was attributed to the loss of mechanical strength as a result of the structural transition of the collagen triple helix to a random coil conformation. The temperature where G' decreased steeply closely matched the onset of denaturation ( $T_{\circ}$ about $34{ }^{\circ} \mathrm{C}$ ) as measured by the micro differential scanning calorimeter, indicating helix to random coil transition (detailed later in section 3.3). Furthermore, as depicted in Figure 3A-C, the addition of waxy starch to different concentrations of collagen pastes resulted in an increase in G' between $68{ }^{\circ} \mathrm{C}$ and $76{ }^{\circ} \mathrm{C}$ and a maximum at $76{ }^{\circ} \mathrm{C}$ with a corresponding decrease in tan $\delta$ values at a temperature of $72{ }^{\circ} \mathrm{C}$. This increase in G' and decrease in $\tan \delta$ can be ascribed to the swelling of the starch granules as a result of the melting of the amylopectin region (Donovan, 1979;Tester and Morrison, 1990;Hsu et al., 2000). However, with further increases in temperature above $76^{\circ} \mathrm{C}$, a decrease in G' was observed for COLLWS pastes which was attributed to the loss of granule integrity and subsequent break down of the starch granules at higher temperature. Similar findings were reported by Sullo and Foster (2010) for waxy maize starch/hydrocolloid mixtures. It was shown in this work that the G' of the mixture increased at about $60{ }^{\circ} \mathrm{C}$ with a further decrease at higher temperatures (Sullo and Foster, 2010). On the contrary, the addition of high amylose starch to different concentrations of collagen paste did not result in an increase in G' at higher temperatures, which means that the granules of amylose starch did not swell under the range of temperatures the rheological measurements 
301 were performed. This is expected, as it has been reported that amylose molecules swell in the 302 temperature range of $104^{\circ} \mathrm{C}$ and $125^{\circ} \mathrm{C}$ (Kibar et al., 2010).

303

304

305

306

307

308

309

310

311

312

313

314

315

316

317

318

319

320

321

322

323

324

325

326

327

328 
(A)
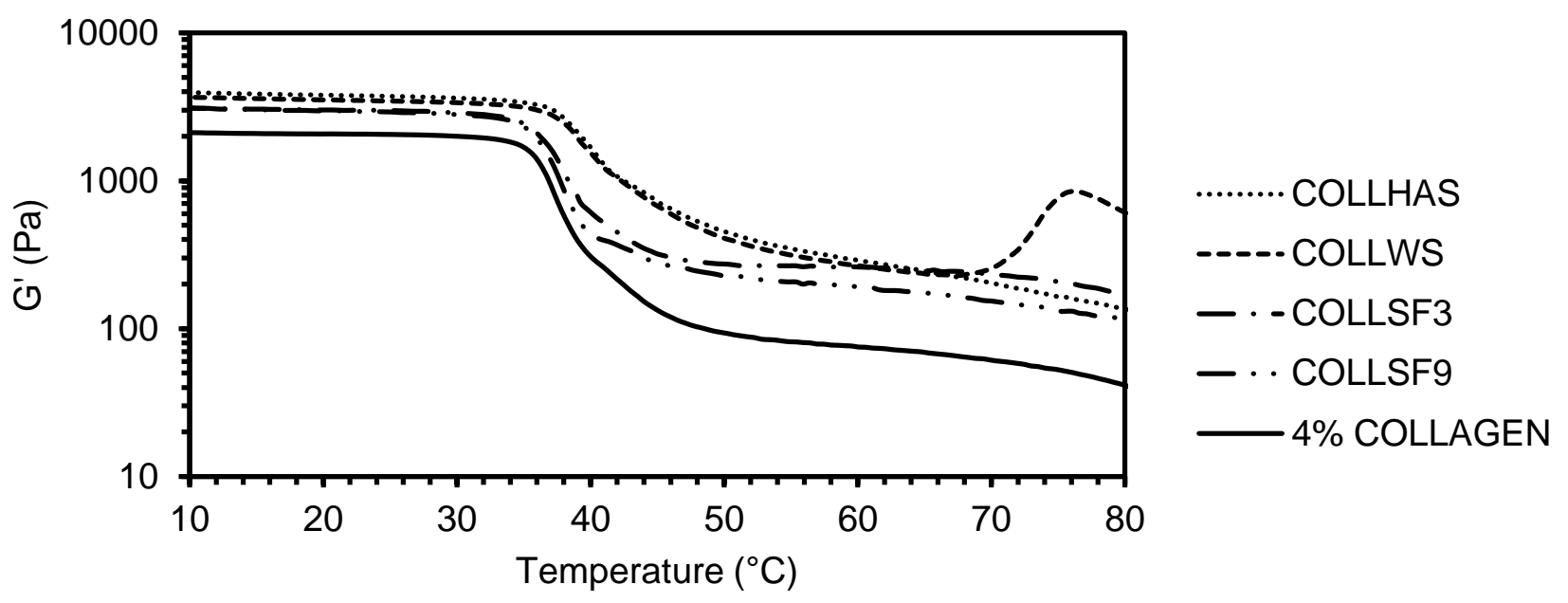

(B)

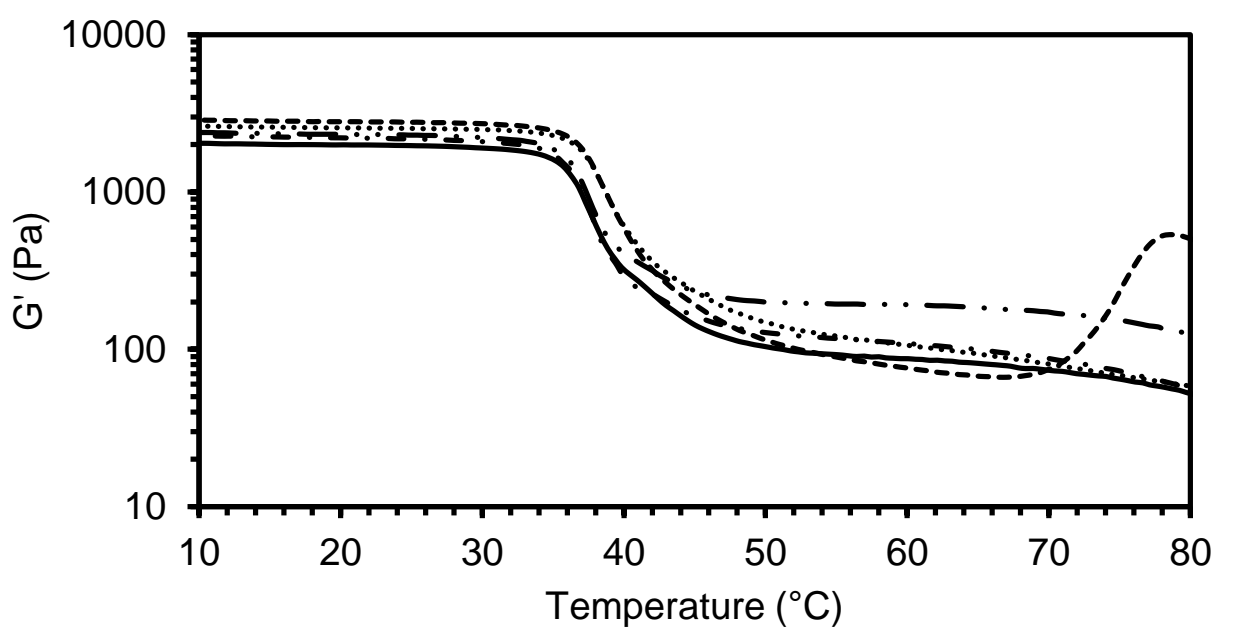

$$
\begin{aligned}
& \text {....... COLLHAS } \\
& -\cdots \text { COLLWS } \\
& -\cdots \text { COLLSF3 } \\
& -\cdots \text { COLLSF9 } \\
& -3.5 \% \text { COLLAGEN }
\end{aligned}
$$

(C)

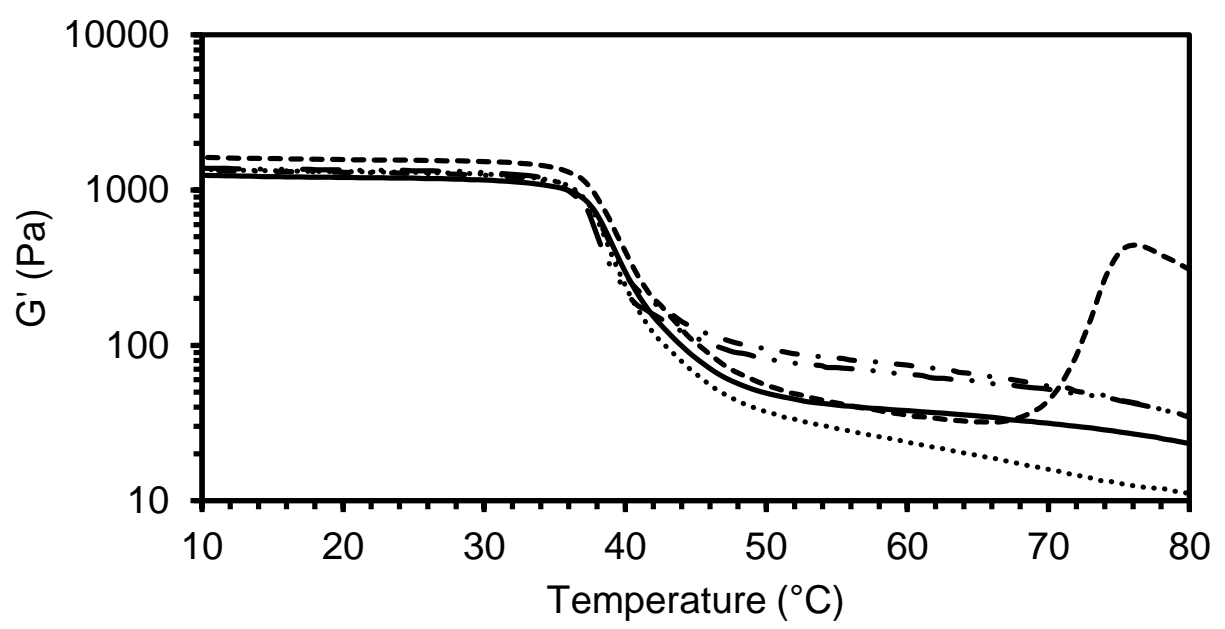

$$
\begin{aligned}
& \cdots . . . . \text { COLLHAS } \\
& -\cdots \text { COLLWS } \\
& -\cdots \text { COLLSF3 } \\
& -\cdots \text { COLLSF9 } \\
& -2.5 \% \text { COLLAGEN }
\end{aligned}
$$

Figure 3. Storage modulus G' as a function of temperature for COLLHAS (…...), COLLWS (----), 
(A)

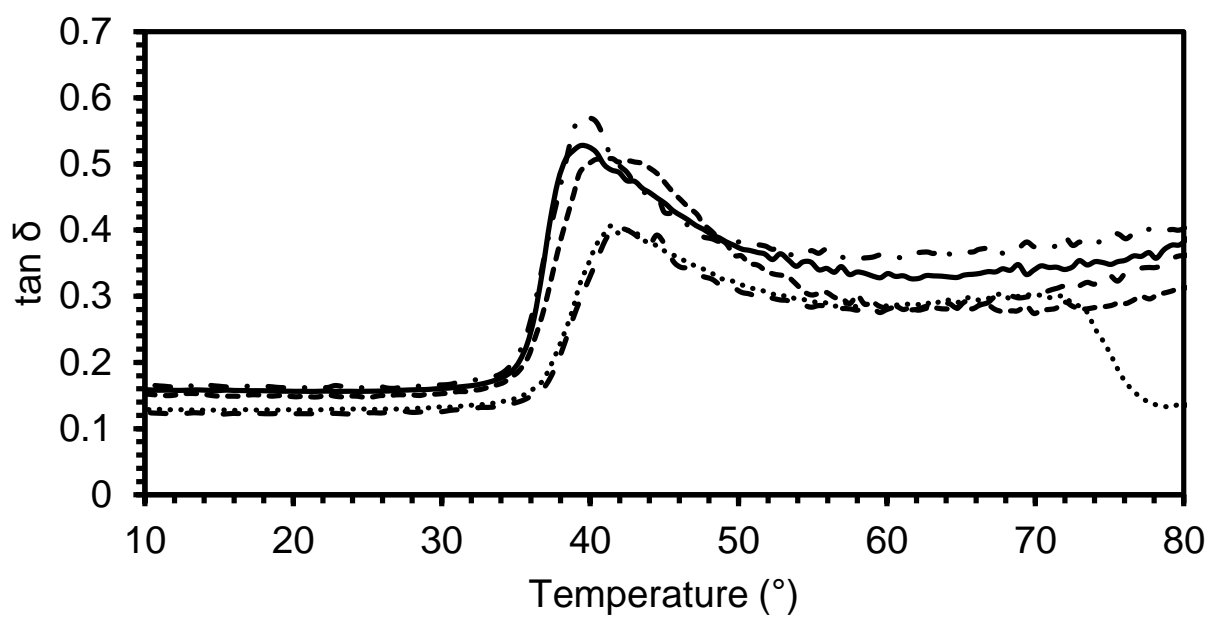

- - COLLHAS COLLWS

-.-.-. COLLSF3

-. - COLLSF9

$4 \%$ COLLAGEN

340

341

(B)

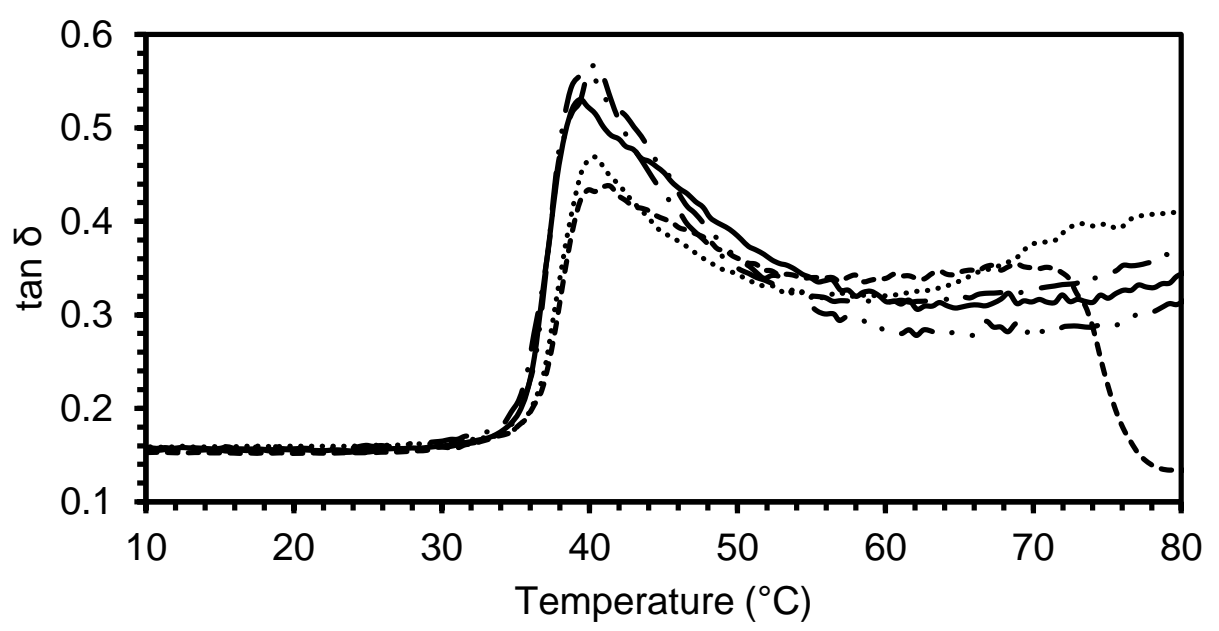

......... COLLHAS

-.-.-. COLLWS

-. - COLLSF3

- $\cdot$ COLLSF9

$3.5 \%$ COLLAGEN

342

343

(C)

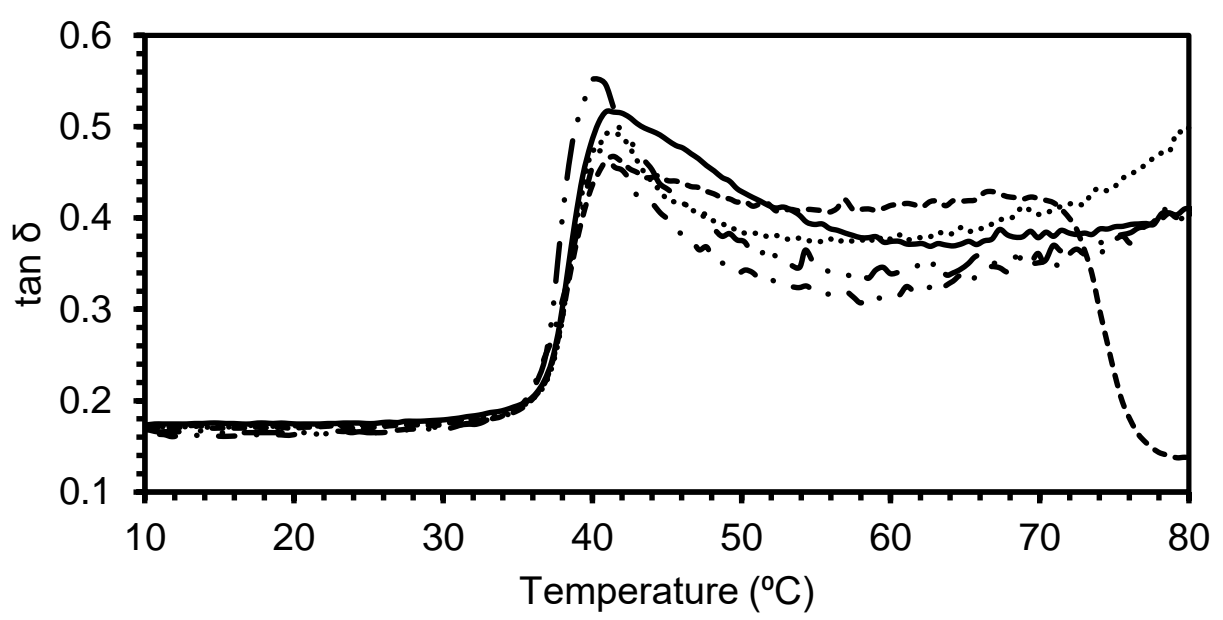

......... COLLHAS

-.-.-. COLLWS

-. - COLLSF3

- . COLLSF9 $2.5 \%$ COLLAGEN

Figure 4. Storage modulus $G^{\prime}$ as a function of temperature for COLLHAS (-.......), COLLWS (----•), 
349 The loss factor $(\tan \delta)$ values of collagen with and without cellulose/starch pastes at the various

350 collagen concentrations were lower than 1 indicating that their overall behaviour was solid-

351 like. Some studies have reported that during oscillatory rheological measurements, the 352 temperature at which tan $\delta$ reached a peak value could be taken as the dynamic denaturation 353 temperature of collagen ( $T_{d d}$ ) (Lai et al., 2008;Zhang et al., 2010;Ding et al., 2014). Hence the 354 dynamic denaturation temperature of COLLSF3, COLLSF9, COLLWS and COLLHAS at the 355 different collagen paste concentrations was recorded as $42^{\circ} \mathrm{C}$, which was slightly higher than 356 that measured by micro DSC $\left(37^{\circ} \mathrm{C}\right)$. In addition, the different measurements report on the 357 melting at different length scales. DSC report on the helix-coil transition directly, whereas the 358 rheological measurement is dependent on the melting and softening of the helical aggregates 359 as the helices melt. This result implies that the thermal denaturation of the collagen triple helix 360 could be influenced by differences in the heating rate used by each instrument. Furthermore, a drastic drop in $\tan \delta$ was observed for all the samples at about $42{ }^{\circ} \mathrm{C}$. This has been attributed to the glass/rubbery transition of the denatured collagen (Pietrucha, 2005). It is also

363 interesting to note that the tan $\delta$ peak value of COLLWS and COLLHAS pastes were lower 364 than that of COLLSF3 and COLLSF9 pastes, indicating that the collagen pastes with starch 365 granules were more rigid in comparison to collagen pastes with cellulose fibres. The lower tan $\delta$ values observed for COLLWS and COLLHAS pastes might be due to the presence of closer packing of the starch granules in the collagen matrix, which reduced the molecular mobility of the collagen triple helix molecules during heating. This is in comparison to cellulose fibres that were not closely attached to the collagen matrix, thus allowing the easy mobility of the collagen chains. Another explanation is that the higher concentrations of starch granules resulted in a stronger network structure which led to an increase in the restriction of the collagen chains and reduction in the damping values. Mohanty suggested that the magnitude of damping factor (tan $\delta)$ peak of composite materials are affected by the incorporation of fillers, the extent of packing and the concentration of the fillers (Mohanty et al., 2006). 


\section{$375 \quad 3.3 \quad$ Thermal properties}

376 The thermal properties of the collagen pastes with and without the addition of cellulose and

377 starch at various mixing ratios are summarised in

378

379

380

381

382

383

384

385

386

387

388

389

390

391

392

393

394

395

396

$397 \quad(\mathrm{~A})$ 


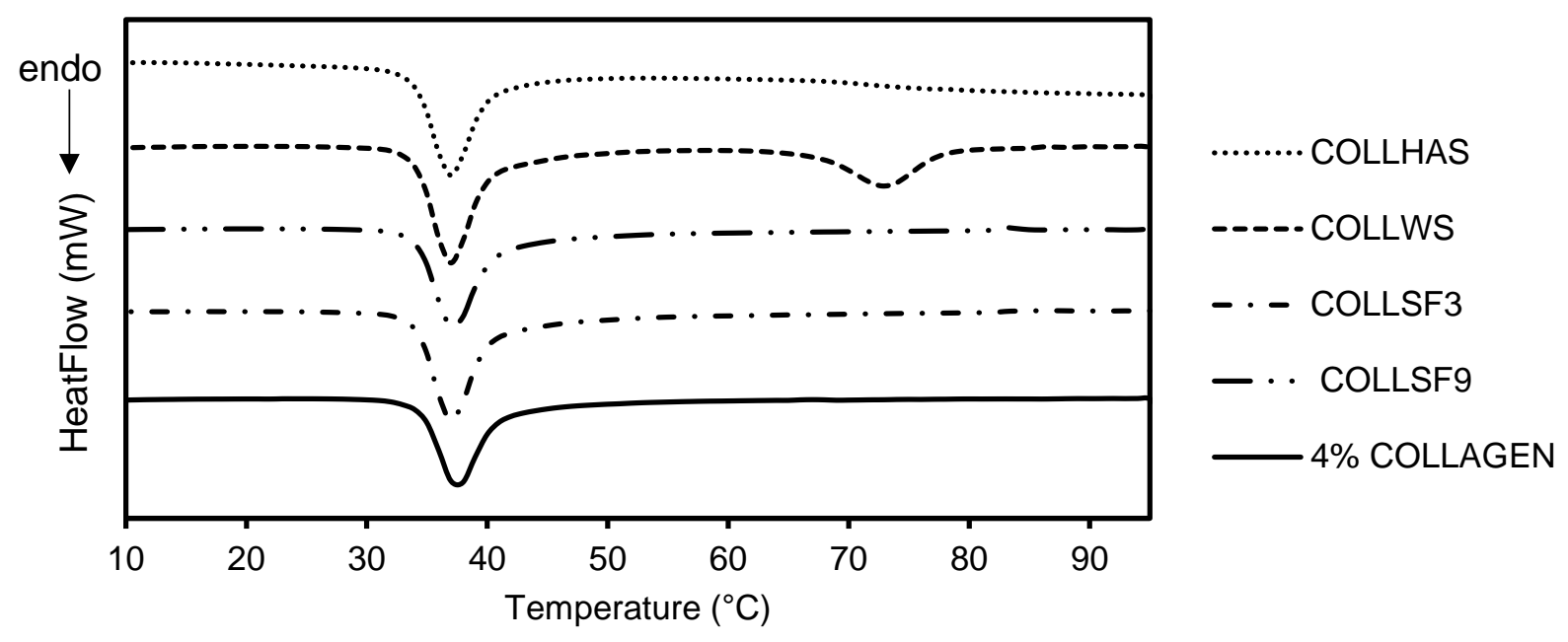

(B)
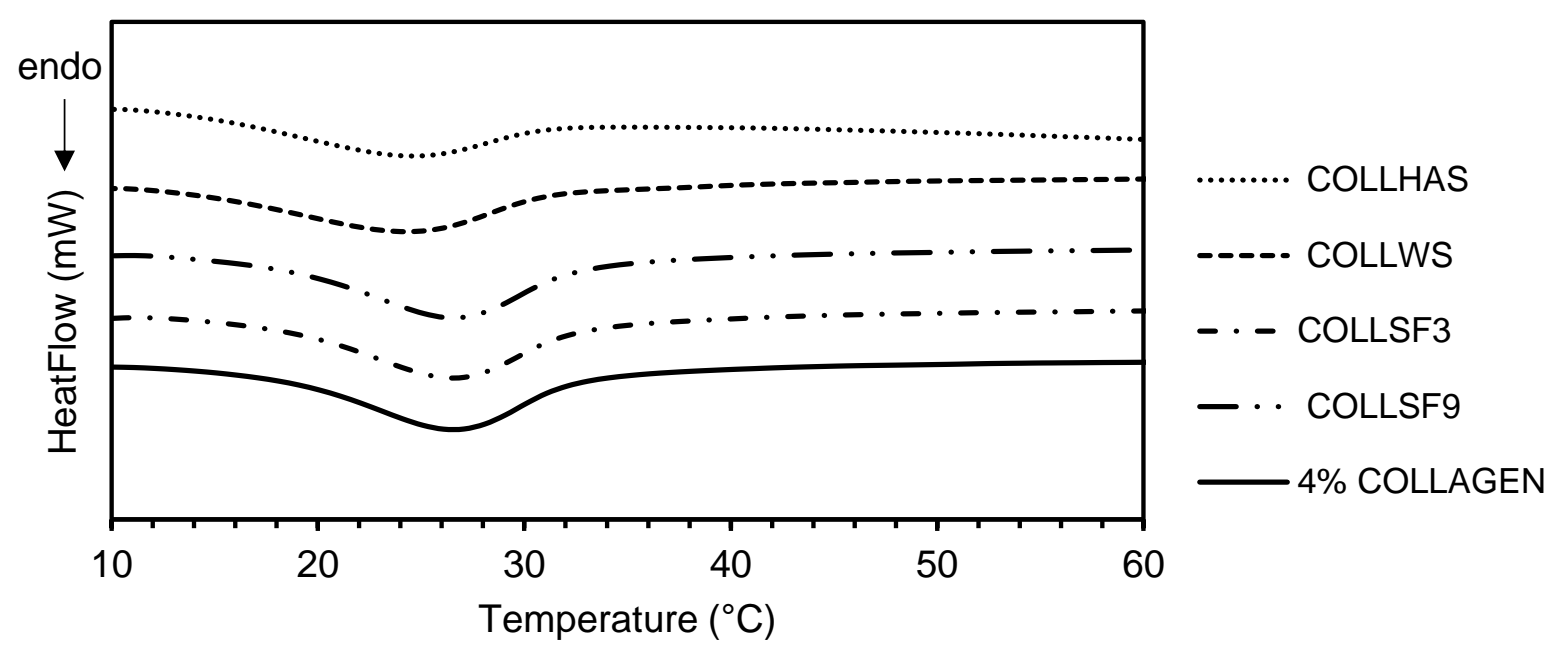

Figure 5. DSC thermograms of (A) first heating and (B) second heating of COLLHAS (

), COLLWS

402 ( ), COLLSF3 ( ), COLLSF9 ( ) and 4\% COLLAGEN ( ) pastes.

403

404

405

406

407

408 
410 formulations) exhibited a single endotherm at approximately $37^{\circ} \mathrm{C}$. The transition temperature

411 was associated with the transition of collagen molecules from the triple helix to a randomly 412 coiled conformation which is induced by the thermal disruption of hydrogen bonds in the 413 collagen molecule (Bigi et al., 2004). In contrast, COLLWS and COLLHAS exhibited two 414 endothermic peaks, the first peak was related to the denaturation of collagen and the second 415 peak corresponds gelatinisation of the starch granules (Figure 5A). Starch gelatinisation 416 involves the irreversible swelling of starch granules when starch is heated in excess water 417 (Morris, 1990;Tester and Morrison, 1990) It was observed that the COLLWS showed a 418 pronounced gelatinisation peak at $73^{\circ} \mathrm{C}$ similar to previous reports (Liu et al., 2006). This endotherm can be attributed to the widely accepted gelatinisation of the amylopectin starch granules which is due to the disruption of the amylopectin crystallites (Donovan, 1979;Tester and Morrison, 1990;Koganti et al., 2011). However, the endotherms for COLLHAS pastes were not as sharp as those of the waxy maize starch which contains mainly amylopectin, instead the beginning of a broad endotherm can be observed from $68^{\circ} \mathrm{C}$. Such a broad peak was also observed previously for corn starch with high amylose content, within the temperature range of 65 to $115^{\circ} \mathrm{C}$ (Liu et al., 2006), suggesting it resulted from a composite consisting of both gelatinisation and a phase transition of the amylose lipid complex. In measurements of pasting properties of high amylose starch up to $140{ }^{\circ} \mathrm{C}$, we have observed gelatinisation peaks beginning at $100{ }^{\circ} \mathrm{C}$ and peaking at $120^{\circ} \mathrm{C}$ (data not shown). Therefore, we would support the fact that the broad peak seen in the DSC endotherms would be consistent with starch-lipid complexes. These results were expected because waxy maize contains about $99 \%$ amylopectin which constitute the crystalline regions of the starch. On the other hand, amylose restricts the swelling of the starch due to the leaching out of amylose during the gelatinisation and formation of complexes with the lipid's presence in starch granules, which limits the rate at which water penetrates into the starch granules. In addition,

435 it was observed that decreasing the collagen concentrations from $4 \%$ to $2.5 \%$ resulted in a 436 slight increase of the peak value temperatures of the collagen/cellulose and collagen/starch 
438 pastes were not significantly different $(P>0.05)$ from pure collagen pastes at the collagen 439 concentrations studied. The endothermic peaks of the COLLSF3, COLLS9, COLLWS and 440 COLLHAS pastes at a mixing ratio of 80:20 observed on reheating are shown Figure 5B and 441 the thermal transition parameters of all formulations are detailed in Table 3 . The endothermic 442 peak appeared at lower temperatures between $24^{\circ} \mathrm{C}-26^{\circ} \mathrm{C}$ (Figure $5 \mathrm{~B}$ ) for all the samples.

443 During the thermal denaturation of collagen, the triple helix is disrupted to give a random coil 444 confirmation (gelatin). However, on cooling, the random coils undergo a conformational 445 disorder-order transition and partly renatures to a triple-helix structure which is similar to that 446 of collagen but with a lower molecular weight (Machado et al., 2002;Bigi et al., 2004). Gilsenan 447 and Ross-Murphy (2000) suggested that lower molecular weight gels melt at lower 448 temperatures than gels of high molecular weight. Also, the lower transition temperature could 449 indicate the formation of lower and less ordered helical bundles as well as reduced helix length 450 (Michon et al., 1997;Aymard et al., 2001). Thus, this might explain the lower denaturation 451 temperatures observed on the second DSC scans. Furthermore, as shown in Table 3, the 452 thermal transitions temperatures of COLLWS and COLLHAS pastes were significantly lower $453(\mathrm{P}<0.05)$ than those of the COLLSF3, COLLSF9 and pure collagen pastes. The decrease in 454 the denaturation temperature and enthalpy can be related to a decrease in the ordering and 455 semi-crystalline nature of the reformed gelatin-like matrix, after collagen melting, upon cooling.

456 Such a decrease might not be expected if the two materials do not affect one another. Lorén 457 et al. (2001) have shown that phase separation and subsequent phase concentration does 458 not impact on the amount of gelatin helices formed. Therefore we do not expect that 459 confinement effects would reduce the ability of the collagen to reform triple helices. Therefore, 460 an unexpected molecular interaction between collagen chains and starch may reduce the 461 creation of gelatin-like network. Indeed, when mixtures highlighted in table 2 are dried, then 462 mixtures containing starch also show a decrease in enthalpy. This is a phenomenon that is 463 currently under further exploration. 
464 Finally, the transition enthalpy for COLLWS pastes was slightly higher than COLLHAS pastes, 465 however, this increase in enthalpy for COLLWS was not significantly different $(P>0.05)$ from 466 enthalpy values of COLLHAS (Table 2). An explanation for this might be due to the high 467 molecular weight and branched chains of amylopectin, indicating a larger amount of energy 468 was needed to melt the regenerated triple helix of the COLLWS paste.

469

470

471

472

473

474

475

476

477

478

479

480

481

482

483

484

485

486

487

$488 \quad(A)$ 


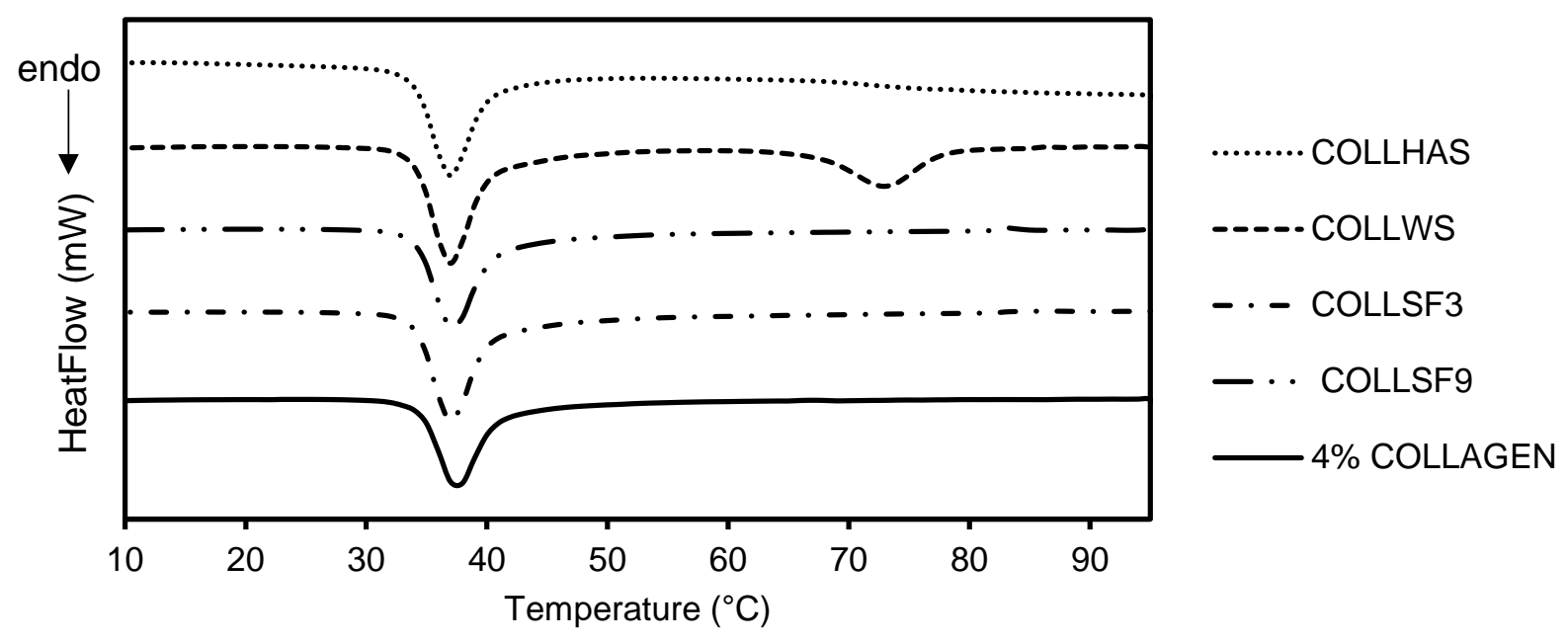

(B)
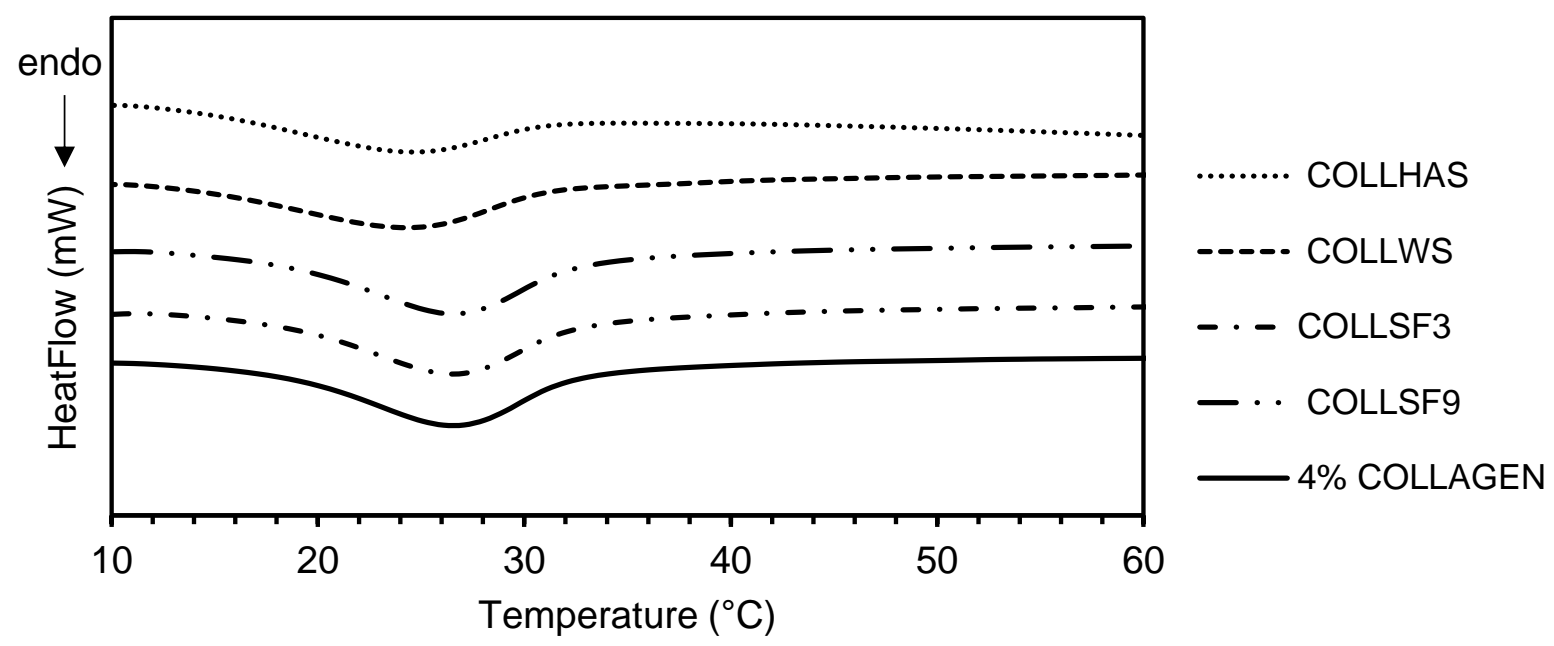

Figure 5. DSC thermograms of (A) first heating and (B) second heating of COLLHAS (……), COLLWS 493 $(---\cdot)$, COLLSF3 $(-\cdot-\cdot)$, COLLSF9 $(-\cdots)$ and $4 \%$ COLLAGEN $(-)$ pastes.

494

495

496

497

498

499 
500 Table 2. DSC parameters after first heating of collagen/cellulose and collagen/starch pastes

501 at different collagen paste concentrations and mixing ratios. $T_{P}=$ peak temperature; $T_{O}=$ Onset

502 temperature; $T_{e}=$ end set temperature and $\Delta \mathrm{H}=$ enthalpy

\begin{tabular}{lcccc}
\hline Samples & $\mathbf{T}_{\text {onset }}\left({ }^{\circ} \mathbf{C}\right)$ & $\mathbf{T}_{\text {Peak }}\left({ }^{\circ} \mathbf{C}\right)$ & $\begin{array}{c}\Delta \mathbf{H}(\mathbf{J} / \mathbf{g} \text { of } \\
\text { collagen })\end{array}$ & $\mathbf{T}_{\text {end }}\left({ }^{\circ} \mathbf{C}\right)$ \\
\hline 4\% COLLAGEN & $33.90 \pm 0.01^{\mathrm{a}}$ & $36.80 \pm 0.02^{\mathrm{a}}$ & $40.36 \pm 0.02^{\mathrm{a}}$ & $0.47 \pm 0.02^{\mathrm{a}}$ \\
COLLSF3 80:20 & $34.00 \pm 0.05^{\mathrm{a}}$ & $37.01 \pm 0.07^{\mathrm{a}}$ & $40.91 \pm 0.05^{\mathrm{a}}$ & $0.43 \pm 0.01^{\mathrm{ab}}$ \\
COLLSF9 80:20 & $33.99 \pm 0.01^{\mathrm{a}}$ & $37.01 \pm 0.00^{\mathrm{a}}$ & $40.60 \pm 0.23^{\mathrm{a}}$ & $0.45 \pm 0.45^{\mathrm{ab}}$ \\
COLLWS 80:20 & $34.05 \pm 0.01^{\mathrm{a}}$ & $36.97 \pm 0.02^{\mathrm{a}}$ & $40.38 \pm 0.00^{\mathrm{a}}$ & $0.46 \pm 0.01^{\mathrm{ab}}$ \\
COLLHAS 80:20 & $34.03 \pm 0.03^{\mathrm{a}}$ & $36.97 \pm 0.02^{\mathrm{a}}$ & $40.37 \pm 0.06^{\mathrm{a}}$ & $0.41 \pm 0.01^{\mathrm{b}}$ \\
3.5\% COLLAGEN & $34.16 \pm 0.07^{\mathrm{a}}$ & $37.23 \pm 0.05^{\mathrm{bc}}$ & $40.91 \pm 0.27^{\mathrm{b}}$ & $0.42 \pm 0.06^{\mathrm{a}}$ \\
COLLSF3 70:30 & $34.10 \pm 0.02^{\mathrm{a}}$ & $37.21 \pm 0.07^{\mathrm{abc}}$ & $40.96 \pm 0.16^{\mathrm{ab}}$ & $0.46 \pm 0.00^{\mathrm{a}}$ \\
COLLSF9 70:30 & $34.17 \pm 0.02^{\mathrm{a}}$ & $37.29 \pm 0.07^{\mathrm{c}}$ & $40.99 \pm 0.99^{\mathrm{b}}$ & $0.49 \pm 0.01^{\mathrm{a}}$ \\
COLLWS 70:30 & $34.12 \pm 0.02^{\mathrm{a}}$ & $37.06 \pm 0.02^{\mathrm{ab}}$ & $40.48 \pm 0.12^{\mathrm{ab}}$ & $0.45 \pm 0.01^{\mathrm{a}}$ \\
COLLHAS 70:30 & $34.01 \pm 0.11^{\mathrm{b}}$ & $37.06 \pm 0.02^{\mathrm{ab}}$ & $40.30 \pm 0.12^{\mathrm{a}}$ & $0.48 \pm 0.02^{\mathrm{a}}$ \\
2.5\% COLLAGEN & $34.63 \pm 0.05^{\mathrm{a}}$ & $37.77 \pm 0.03^{\mathrm{a}}$ & $41.63 \pm 0.08^{\mathrm{a}}$ & $0.48 \pm 0.00^{\mathrm{b}}$ \\
COLLSF3 50:50 & $34.46 \pm 0.07^{\mathrm{a}}$ & $37.66 \pm 0.09^{\mathrm{a}}$ & $41.09 \pm 0.03^{\mathrm{a}}$ & $0.45 \pm 0.01^{\mathrm{ab}}$ \\
COLLSF9 50:50 & $34.62 \pm 0.04^{\mathrm{a}}$ & $37.77 \pm 0.07^{\mathrm{a}}$ & $41.49 \pm 0.03^{\mathrm{a}}$ & $0.44 \pm 0.00^{\mathrm{ab}}$ \\
COLLWS 50:50 & $34.35 \pm 0.36^{\mathrm{a}}$ & $37.79 \pm 0.15^{\mathrm{a}}$ & $41.02 \pm 0.06^{\mathrm{a}}$ & $0.40 \pm 0.01^{\mathrm{a}}$ \\
COLLHAS 50:50 & $34.63 \pm 0.01^{\mathrm{a}}$ & $37.67 \pm 0.02^{\mathrm{a}}$ & $41.01 \pm 0.13^{\mathrm{a}}$ & $0.42 \pm 0.00^{\mathrm{ab}}$
\end{tabular}


505 Table 3. DSC parameters (second heating) of collagen/cellulose and collagen/starch at 506 various collagen concentrations $(4 \%, 3.5 \%$ and $2.5 \%) . \mathrm{T}_{\mathrm{P}}=$ peak temperature; $\mathrm{T}_{\mathrm{O}}=$ Onset 507 temperature; $\mathrm{Te}=$ end set temperature and $\Delta \mathrm{H}=$ enthalpy

\begin{tabular}{lcccc}
\hline Samples & $\mathbf{T}_{\text {onset }}\left({ }^{\circ} \mathbf{C}\right)$ & $\mathbf{T}_{\text {Peak }}\left({ }^{\circ} \mathbf{C}\right)$ & $\begin{array}{c}\Delta \mathbf{H}(\mathbf{J} / \mathbf{g} \text { of } \\
\text { denatured } \\
\text { collagen })\end{array}$ & $\mathbf{T}_{\text {end }}\left({ }^{\circ} \mathbf{C}\right)$ \\
\hline $4 \%$ COLLAGEN & $17.67 \pm 0.11^{\mathrm{b}}$ & $26.66 \pm 0.11^{\mathrm{b}}$ & $0.27 \pm 0.01^{\mathrm{c}}$ & $33.29 \pm 0.14^{\mathrm{b}}$ \\
COLLSF3 80:20 & $17.68 \pm 0.13^{\mathrm{b}}$ & $26.49 \pm 0.05^{\mathrm{b}}$ & $0.27 \pm 0.00^{\mathrm{c}}$ & $33.38 \pm 0.05^{\mathrm{b}}$ \\
COLLSF9 80:20 & $17.46 \pm 0.10^{\mathrm{b}}$ & $26.55 \pm 0.02^{\mathrm{b}}$ & $0.27 \pm 0.01^{\mathrm{c}}$ & $33.41 \pm 0.05^{\mathrm{b}}$ \\
COLLWS 80:20 & $13.76 \pm 0.20^{\mathrm{a}}$ & $24.37 \pm 0.09^{\mathrm{a}}$ & $0.18 \pm 0.00^{\mathrm{b}}$ & $31.67 \pm 0.00^{\mathrm{a}}$ \\
COLLHAS 80:20 & $14.33 \pm 0.42^{\mathrm{a}}$ & $24.22 \pm 0.00^{\mathrm{a}}$ & $0.14 \pm 0.01^{\mathrm{a}}$ & $31.33 \pm 0.03^{\mathrm{a}}$ \\
3.5\% COLLAGEN & $18.13 \pm 0.05^{\mathrm{b}}$ & $26.81 \pm 0.04^{\mathrm{b}}$ & $0.26 \pm 0.00^{\mathrm{b}}$ & $33.60 \pm 0.04^{\mathrm{b}}$ \\
COLLSF3 70:30 & $18.09 \pm 0.13^{\mathrm{b}}$ & $26.79 \pm 0.04^{\mathrm{b}}$ & $0.27 \pm 0.00^{\mathrm{b}}$ & $33.61 \pm 0.02^{\mathrm{b}}$ \\
COLLSF9 70:30 & $19.07 \pm 0.17^{\mathrm{b}}$ & $26.72 \pm 0.02^{\mathrm{b}}$ & $0.27 \pm 0.00^{\mathrm{b}}$ & $33.57 \pm 0.00^{\mathrm{b}}$ \\
COLLWS 70:30 & $14.06 \pm 0.37^{\mathrm{a}}$ & $24.45 \pm 0.02^{\mathrm{a}}$ & $0.18 \pm 0.00^{\mathrm{a}}$ & $31.47 \pm 0.02^{\mathrm{a}}$ \\
COLLHAS 70:30 & $14.14 \pm 0.37^{\mathrm{a}}$ & $24.22 \pm 0.09^{\mathrm{a}}$ & $0.16 \pm 0.01^{\mathrm{a}}$ & $31.41 \pm 0.01^{\mathrm{a}}$ \\
2.5\% COLLAGEN & $18.96 \pm 0.04^{\mathrm{b}}$ & $27.35 \pm 0.02^{\mathrm{b}}$ & $0.24 \pm 0.02^{\mathrm{b}}$ & $33.98 \pm 0.06^{\mathrm{b}}$ \\
COLLSF3 50:50 & $19.21 \pm 0.36^{\mathrm{b}}$ & $27.48 \pm 0.09^{\mathrm{b}}$ & $0.23 \pm 0.02^{\mathrm{b}}$ & $33.89 \pm 0.16^{\mathrm{b}}$ \\
COLLSF9 50:50 & $19.13 \pm 0.02^{\mathrm{b}}$ & $27.38 \pm 0.02^{\mathrm{b}}$ & $0.24 \pm 0.00^{\mathrm{b}}$ & $34.02 \pm 0.08^{\mathrm{b}}$ \\
COLLWS 50:50 & $15.48 \pm 0.07^{\mathrm{a}}$ & $25.08 \pm 0.11^{\mathrm{a}}$ & $0.14 \pm 0.01^{\mathrm{a}}$ & $31.80 \pm 0.02^{\mathrm{a}}$ \\
COLLHAS 50:50 & $15.98 \pm 0.20^{\mathrm{a}}$ & $24.99 \pm 0.06^{\mathrm{a}}$ & $0.12 \pm 0.01^{\mathrm{a}}$ & $31.56 \pm 0.13^{\mathrm{a}}$
\end{tabular}

508

509

510

511 The elastic properties of collagen pastes were modified by the addition of fillers i.e. cellulose

512 fibres and starch granules at a range of different collagen concentrations. The results indicate

513 that different materials, when matched for phase volumes, have very different effects on the elastic properties of collagen pastes. In addition, these materials did not affect the thermal

a-c Mean \pm standard deviation. Means in the same column with different superscript letters are significanlty different $(\mathrm{P}<0.05)$.

\section{Conclusions} stability of collagen. However, on reheating, the addition of starch granules had an impact on 
516 the melting of denatured collagen. The findings in this study may serve as a platform to

517 improve the rheological properties and processing performance of collagen pastes in order to

518 improve their product or processing performance. Further research is still necessary to

519 understand the mechanisms or interactions underlying the effect of starch granules on the

melting of denatured collagen.

521

\section{Acknowledgements}

522

523

524

525

526

527

528

529

530

531

532

533

534

535

536

537

538

539

540

541

542

543

544

545

546

547

548

549

550

551

The authors would like to acknowledge the financial support obtained from Engineering and

Physical Sciences Research Council (EP/M50810X/1), in collaboration with Devro Plc.

\section{References}

Ang, J. \& Miller, W. 1991. Multiple functions of powdered cellulose as a food ingredient. Cereal foods world (USA).

Aymard, P., Martin, D. R., Plucknett, K., Foster, T. J., Clark, A. H. \& Norton, I. T. 2001. Influence of thermal history on the structural and mechanical properties of agarose gels. Biopolymers: Original Research on Biomolecules, 59, 131-144.

Barbut, S. 2010. Microstructure of naturalextruded and co-extruded collagen casings before and after heating. Italian Journal of Food Science, 22, 126-133.

Basiak, E., Lenart, A. \& Debeaufort, F. 2017. Effect of starch type on the physico-chemical properties of edible films. International journal of biological macromolecules, 98, 348-356.

Bigi, A., Panzavolta, S. \& Rubini, K. 2004. Relationship between triple-helix content and mechanical properties of gelatin films. Biomaterials, 25, 5675-5680.

Bledzki, A. K. \& Gassan, J. 1999. Composites reinforced with cellulose based fibres. Progress in Polymer Science, 24, 221-274.

Buléon, A., Colonna, P., Planchot, V. \& Ball, S. 1998. Starch granules: structure and biosynthesis. International Journal of Biological Macromolecules, 23, 85-112.

Copeland, L., Blazek, J., Salman, H. \& Tang, M. C. 2009. Form and functionality of starch. Food Hydrocolloids, 23, 1527-1534.

Ding, C., Zhang, M. \& Li, G. 2014. Rheological properties of collagen/hydroxypropyl methylcellulose (COL/HPMC) blended solutions. Journal of Applied Polymer Science, 131.

Donovan, J. W. 1979. Phase transitions of the starch-water system. Biopolymers, 18, 263-275. 
Dufresne, A. \& Vignon, M. R. 1998. Improvement of starch film performances using cellulose microfibrils. Macromolecules, 31, 2693-2696.

Friess, W. 1998. Collagen-biomaterial for drug delivery. European Journal of Pharmaceutics and Biopharmaceutics, 45, 113-136.

Gilsenan, P. M. \& Ross-Murphy, S. B. 2000. Viscoelasticity of thermoreversible gelatin gels from mammalian and piscine collagens. Journal of Rheology, 44, 871-883.

Harris, P. J. \& Smith, B. G. 2006. Plant cell walls and cell-wall polysaccharides: structures, properties and uses in food products. International journal of food science \& technology, 41, 129-143.

Hashim, P., Sofberi, M., Ridzwan, M., Bakar, J. \& Mat Hashim, D. 2015. Collagen in food and beverage industries. International Food Research Journal, 22, 1-8.

Hemar, Y., Lebreton, S., Xu, M. \& Day, L. 2011. Small-deformation rheology investigation of rehydrated cell wall particles-xanthan mixtures. Food Hydrocolloids, 25, 668-676.

Hsu, S., Lu, S. \& Huang, C. 2000. Viscoelastic changes of rice starch suspensions during gelatinization. Journal of Food Science, 65, 215-220.

Jane, J., Chen, Y., Lee, L., Mcpherson, A., Wong, K., Radosavljevic, M. \& Kasemsuwan, T. 1999. Effects of amylopectin branch chain length and amylose content on the gelatinization and pasting properties of starch. Cereal Chemistry, 76, 629-637.

Kibar, E. a. A., Gönenç, İ. \& Us, F. 2010. Gelatinization of waxy, normal and high amylose corn starches. The Journal of Food, 35, 237-244.

Koganti, N., Mitchell, J. R., Ibbett, R. N. \& Foster, T. J. 2011. Solvent effects on starch dissolution and gelatinization. Biomacromolecules, 12, 2888-2893.

Komsa-Penkova, R., Koynova, R., Kostov, G. \& Tenchov, B. G. 1996. Thermal stability of calf skin collagen type $\mathrm{I}$ in salt solutions. Biochimica et Biophysica Acta (BBA)-Protein Structure and Molecular Enzymology, 1297, 171-181.

Lai, G., Li, Y. \& Li, G. 2008. Effect of concentration and temperature on the rheological behavior of collagen solution. International Journal of Biological Macromolecules, 42, 285-291.

Liu, H., Yu, L., Xie, F. \& Chen, L. 2006. Gelatinization of cornstarch with different amylose/amylopectin content. Carbohydrate Polymers, 65, 357-363.

Lorén, N., Hermansson, A.-M., Williams, M., Lundin, L., Foster, T., Hubbard, C., Clark, A., Norton, I., Bergström, E. \& Goodall, D. 2001. Phase separation induced by conformational ordering of gelatin in gelatin/maltodextrin mixtures. Macromolecules, 34, 289-297.

Machado, A. S., Martins, V. \& Plepis, A. 2002. Thermal and Rheological Behavior of Collagen. Chitosan blends. Journal of Thermal Analysis and Calorimetry, 67, 491-498.

Michon, C., Cuvelier, G., Relkin, P. \& Launay, B. 1997. Influence of thermal history on the stability of gelatin gels. International journal of biological macromolecules, 20, 259-264. 
Mohammed, I., Ahmed, A. R. \& Senge, B. 2011. Dynamic rheological properties of chickpea and wheat flour dough's. Journal of Applied Sciences, 11, 3405-3412.

Mohanty, S., Verma, S. K. \& Nayak, S. K. 2006. Dynamic mechanical and thermal properties of MAPE treated jute/HDPE composites. Composites Science and Technology, 66, 538-547.

Morris, V. 1990. Starch gelation and retrogradation. Trends in Food Science \& Technology, 1, 2-6.

Mu, C., Li, D., Lin, W., Ding, Y. \& Zhang, G. 2007. Temperature induced denaturation of collagen in acidic solution. Biopolymers: Original Research on Biomolecules, 86, 282-287.

Nicoleti, J. \& Telis, V. 2009. Viscoelastic and thermal properties of collagenxanthan gum and collagen-maltodextrin suspensions during heating and cooling. Food Biophysics, 4, 135.

Oechsle, A. M., Häupler, M., Gibis, M., Kohlus, R. \& Weiss, J. 2015. Modulation of the rheological properties and microstructure of collagen by addition of co-gelling proteins. Food Hydrocolloids, 49, 118-126.

Pati, F., Adhikari, B. \& Dhara, S. 2010. Isolation and characterization of fish scale collagen of higher thermal stability. Bioresource Technology, 101, 3737-3742.

Philipse, A. P. 1996. The random contact equation and its implications for (colloidal) rods in packings, suspensions, and anisotropic powders. Langmuir, 12, 1127-1133.

Pietrucha, K. 2005. Changes in denaturation and rheological properties of collagen-hyaluronic acid scaffolds as a result of temperature dependencies. International journal of biological macromolecules, 36, 299-304.

Ross - Murphy, S. B. 1995. Rheological characterisation of gels. Journal of Texture Studies, 26, 391-400.

Schroepfer, M. \& Meyer, M. 2017. DSC investigation of bovine hide collagen at varying degrees of crosslinking and humidities. International Journal of Biological Macromolecules, 103, 120-128.

Singh, N., Singh, J., Kaur, L., Sodhi, N. S. \& Gill, B. S. 2003. Morphological, thermal and rheological properties of starches from different botanical sources. Food Chemistry, 81, 219-231.

Sullo, A. \& Foster, T. J. 2010. Characterisation of Starch/Cellulose blends. Annual Transactions of the Nordic Rheology, 18, 1-7.

Tatsumi, D., Ishioka, S. \& Matsumoto, T. 2002. Effect of fiber concentration and axial ratio on the rheological properties of cellulose fiber suspensions. Nihon Reoroji Gakkaishi, 30, 27-32.

Tester, R. F. \& Morrison, W. R. 1990. Swelling and gelatinization of cereal starches. I. Effects of amylopectin, amylose, and lipids. Cereal Chemistry, 67, 551-557.

Wang, K., Wang, W., Ye, R., Liu, A., Xiao, J., Liu, Y. \& Zhao, Y. 2017. Mechanical properties and solubility in water of corn starch-collagen 
composite films: Effect of starch type and concentrations. Food Chemistry, 216, 209-216.

644 Wang, W., Zhang, X., Li, C., Du, G., Zhang, H. \& Ni, Y. 2018. Using 645 carboxylated cellulose nanofibers to enhance mechanical and barrier properties of collagen fiber film by electrostatic interaction. Journal of the Science of Food and Agriculture, 98, 3089-3097.

Wolf, K., Sobral, P. \& Telis, V. 2009. Physicochemical characterization of collagen fibers and collagen powder for self-composite film production. Food Hydrocolloids, 23, 1886-1894.

Yoon, K. \& Lee, C. 1990. Effect of powdered cellulose on the texture and freeze - thaw stability of surimi - based shellfish analog products. Journal of food science, 55, 87-91.

Zhang, M., Chen, Y., Li, G. \& Du, Z. 2010. Rheological properties of fish skin 656 collagen solution: Effects of temperature and concentration. KoreaAustralia Rheology Journal, 22, 119-127. 